\title{
Central Artery Pulse Pressure in End-Stage Renal Disease: The Roles of Aortic Diameter, Aortic Stiffness and Wave Reflection
}

\author{
B. Pannier ${ }^{a}$ b $\quad$ A.P. Guérin ${ }^{a, b} \quad$ S.J. Marchais ${ }^{a}$ M.E. Safarc G.M. London ${ }^{a}$ b \\ a Service de Néphrologie, Centre Hospitalier Manhès, Fleury-Mérogis, et ${ }^{b}$ INSERM U970, Pharmacologie, \\ Hôpital Européen Georges Pompidou, Assistance Publique - Hôpitaux de Paris, et ${ }^{\mathrm{C}} \mathrm{Hôpital} \mathrm{Hotel} \mathrm{Dieu,}$ \\ Assistance Publique - Hôpitaux de Paris, Paris, France
}

\section{Key Words}

Carotid artery $\cdot$ Pulse pressure $\cdot$ Arterial stiffness $\cdot$ Wave reflections - Aortic diameter $\cdot$ Characteristic impedance . End-stage renal disease

\begin{abstract}
In elderly subjects and patients with end-stage renal disease (ESRD), carotid pulse pressure (PP) is an independent and significant predictor of cardiovascular (CV) risk. Whereas in the elderly carotid diameter, but not carotid stiffness, is an associated CV risk factor, an opposite CV risk pattern was observed in ESRD patients that was associated with stiffness. Whether in ESRD patients arterial diameter, stiffness or both are involved in the mechanism(s) of increased carotid PP has never been investigated. Nondiabetic ESRD patients ( $n=$ 144) were compared with 57 control subjects matched for age, sex and mean blood pressure, but with higher brachial and carotid PP. Noninvasive echo-Doppler techniques and pulse wave velocity (PWV) and pulse wave analysis were used to evaluate cardiac and carotid arterial structures and functions using multiple stepwise regressions. In controls, carotid PP was associated only with stroke volume, arterial wave reflections and aortic PWV, but not aortic diameter. In ESRD patients, it was associated with wave reflections, aortic PWV, stroke volume and higher aortic diameter. In ESRD patients and controls, elevated carotid PP mainly reflected increased aortic PWV and earlier wave reflections. Aortic diam-
\end{abstract}

eter had an impact only on ESRD patients, where it compensated for enhanced aortic stiffness and the more pronounced effect of reflected waves. This hemodynamic profile differs consistently from that in elderly subjects of the general population and selectively influences CV risk and drug treatment.

Copyright $\odot 2011$ S. Karger AG, Basel

Increased aortic stiffness and associated elevated pulse pressure (PP) in central arteries has emerged as a strong and independent predictor of cardiovascular (CV) events in general population [1] and patients with end-stage renal disease (ESRD) [2]. The pressure wave is produced by the flow wave in the proximal aorta (forward pressure, Pf) and propagated towards the periphery where it is reflected back (reflected pressure, Pr). Recent results obtained in ESRD patients showed that increased aortic stiffness predicted CV events, pointing to the primary role of abnormal aortic function in the pathogenesis of observed arterial abnormalities in uremic patients [3]. The hemodynamic parameters used as surrogate measurements of aortic stiffness are pulse wave velocity (PWV) and proximal aorta characteristic impedance $(\mathrm{Zc})$. While these arterial stiffness parameters are related, they have important differences [4]. Indeed, PWV is relatively insensitive to geometric changes of the proximal aorta (aortic diameter), while aortic dimensions play a

Dr. Gérard London

Centre Hospitalier Manhès

8 rue Roger Clavier

FR-91712 Fleury-Mérogis Cedex (France)

Tel. +33 16925 6485, Fax +3316925 6525, E-Mail glondon@ @lub-internet.fr 
fundamental role as $\mathrm{Zc}$ determinant. The second important point is the strong PWV dependency on mean blood pressure (MBP), which is not observed with Zc.

$\mathrm{Zc}$, which is an indicator of the pressure generated by a given flow in the proximal aorta, has not been evaluated in ESRD patients. This study was designed to evaluate the respective roles of aortic stiffness and aortic $\mathrm{Zc}$ on $\mathrm{PP}$ in central arteries in ESRD patients in comparison with age-, sex- and MBP-matched control subjects.

\section{Methods}

\section{Participants}

The study included 144 nondiabetic ESRD patients and 57 age, sex- and MBP-matched healthy controls. Patients were enrolled if: (a) they had been on hemodialysis for at least 3 months; (b) they agreed to participate in the study, which was approved by our Institutional Review Board; (c) they were free of any CV complication during the 6 months preceding entry into the study, and (d) they had no hemodynamically significant aortic valvular stenosis evaluated echocardiographically.

\section{Hemodynamic Data}

Investigations were performed in a controlled environment kept at $22 \pm 2{ }^{\circ} \mathrm{C}( \pm 1$ standard error of the mean - SEM $)$. Brachial artery BP was measured with a mercury sphygmomanometer with cuffs adapted to arm circumference after the subjects had been recumbent for at least $15 \mathrm{~min}$. Systolic BP (SBP) was taken at phase I of the Korotkoff sounds and diastolic BP (DBP) at phase V. MBP was computed from the integral of the crosssectional area of the radial artery pressure waveform recorded by applanation tonometry (see below) and corresponding to an R-R interval. Peripheral (brachial) PP was calculated as the difference between brachial SBP and DBP.

Aortic PWV was automatically measured with a dedicated validated device (Complior ${ }^{\circledR}$, Colson, Les Lilas, France), as previously described [5-7]. Simultaneously, recorded pulse waveforms were obtained transcutaneously over the common carotid and femoral arteries in the groin, and PWV was calculated as the distance between recording sites measured over the surface of the body, divided by the time interval between the feet of the flow waves. This interval was averaged over 10-15 cardiac cycles. Reproducibility was published previously [5].

\section{Central (Common Carotid Artery) BP}

The amplitude and timing of wave reflections were evaluated noninvasively by applanation tonometry, as previously detailed, using an automated device (Sphygmocor ${ }^{\circledR}$, Sydney, Australia) [7]. The device evaluates the pressure (Ps) at the shoulder of the systolic part of the curve, late systolic peak (Ppk) above the shoulder $(\Delta \mathrm{P})$, attributable to the return of wave reflections. The ratio between $\Delta \mathrm{P}$ and carotid artery $\mathrm{PP}(\Delta \mathrm{P} / \mathrm{PP})$ defines an augmentation index (\%), which is an estimate of the relative wave reflection effect on pressure in central arteries. Carotid artery SBP and PP were calculated from the recorded carotid artery pressure waveform after calibration with the brachial artery DBP and MBP. Forward (Pf) and reflected ( $\mathrm{Pr}$ ) pressure waves were estimated in the time domain according to following relationships: $\mathrm{Pf}=(\mathrm{PP}+$ $\mathrm{ZcQ}) / 2$ and $\mathrm{Pr}=(\mathrm{PP}-\mathrm{ZcQ}) / 2$, where $\mathrm{PP}$ is carotid $\mathrm{PP}$ and the $\mathrm{Q}$ corresponding flow (stroke volume/left ventricular, $\mathrm{LV}$, ejection time in $\mathrm{ml} / \mathrm{s}$ ), and $\mathrm{Zc}$ is characteristic impedance (see below) [8].

\section{Aortic Determinations}

Two-dimensionally directed M-mode echocardiography was performed with an HP Sonos 100 (Hewlett Packard Company, Evry, France) using 2.5- and 3.R-MHz transducers simultaneously with carotid artery tonometry [5]. The ascending aorta diameter $2 \mathrm{~cm}$ above its root was measured on longitudinal and transversal scans, and the internal diameter was expressed as the average value. Aortic flow velocity was evaluated using pulsed Doppler measurements on the apical four-chamber view of the heart. The sample volume was positioned in the inflow area just at the tip of the aortic leaflets. Flow velocity was determined by spectral analysis of the digitized broadband Doppler audio signal. Stroke volume was calculated as the aortic annular cross-sectional area multiplied by the velocity integral of flow-velocity outflow, and cardiac output $(\mathrm{CO})$ as stroke volume multiplied by heart rate. Total peripheral resistance $(\mathrm{Zr})$ was estimated with the $\mathrm{MBP} / \mathrm{CO}$ ratio as published elsewhere [5]. Peak flow was calculated from aortic annular cross-sectional area and maximal aortic flow velocity. Zc was estimated in the time domain as described previously: the point at which flow reaches $95 \%$ of its peak value was located on the flow tracing $\left(\mathrm{Q}_{95}\right)$, and enables determination of the carotid pressure changes from the foot to the time of $\mathrm{Q}_{95}\left(\mathrm{P}_{Z}\right)$. $\mathrm{Zc}_{\mathrm{c}}$ is computed from these two values: $\mathrm{Zc}_{\mathrm{c}}=\mathrm{P}_{\mathrm{Z}} / \mathrm{Q}_{95}$ [9].

\section{Statistical Analyses}

Data are expressed as medians or means \pm SEM as function of the normality of distribution. Quantitative variables with non-normal distribution (CRP) were log-transformed to achieve normal distributions. Continuous variables were compared using Student's $\mathrm{t}$ test or the Mann-Whitney test. Frequency differences were tested by $\chi^{2}$ analysis. Sex (0, male; 1 , female) was used as dummy variables. Stepwise regression was used to analyze associations between aortic and arterial parameters with different variables. Differences were considered significant at $\mathrm{p}<0.05$. All tests were performed using NCSS 2000 software (J. Hintze, Kaysville, Utah, USA).

\section{Results}

Clinical characteristics of the study populations are reported in table 1 . The two groups had comparable age and sex distributions, with ESRD patients having lower weight, height and body mass index, and typical diseaseassociated blood chemistry changes, including microinflammation characterized by lower serum albumin, and higher CRP and fibrinogen, higher triglycerides and lower hemoglobin.

Hemodynamic parameters are given in table 2. ESRD patients had higher brachial and central SBP and PP with comparable mean and lower DBP. The augmentation index was higher in ESRD patients as were their forward and 
Table 1. Baseline characteristics

\begin{tabular}{lccc}
\hline Variable & Controls & $\begin{array}{l}\text { ESRD } \\
\text { patients }\end{array}$ & $\begin{array}{l}\text { p } \\
\text { value }\end{array}$ \\
\hline Age, years & $45.8 \pm 1.7$ & $48.6 \pm 1.3$ & $\mathrm{NS}$ \\
Weight, kg & $76 \pm 2.05$ & $64 \pm 1.75$ & $<0.001$ \\
Height, m & $1.70 \pm 0.01$ & $1.65 \pm 0.02$ & $<0.001$ \\
Body surface area, m & $1.88 \pm 0.03$ & $1.70 \pm 0.02$ & $<0.001$ \\
Body mass index & $26.5 \pm 0.6$ & $23.5 \pm 0.3$ & $<0.0001$ \\
Male/female & $38 / 19$ & $95 / 49$ & $\mathrm{NS}$ \\
Total cholesterol, mM & $5.20 \pm 0.42$ & $5.0 \pm 0.12$ & $\mathrm{NS}$ \\
HDL cholesterol, mM & $1.12 \pm 0.15$ & $1.08 \pm 0.1$ & $\mathrm{NS}$ \\
LDL cholesterol, mM & $3.40 \pm 0.32$ & $3.52 \pm 0.10$ & $\mathrm{NS}$ \\
Triglycerides, mM & $1.12 \pm 0.15$ & $1.83 \pm 0.10$ & $<0.0001$ \\
Serum albumin, g/l & $43.7 \pm 1.2$ & $40.7 \pm 0.30$ & $<0.001$ \\
C-reactive protein, mg/l & $1.25 \pm 0.15$ & $10 \pm 0.8$ & $<0.0001$ \\
Fibrinogen, g/l & $2.72 \pm 0.10$ & $4.32 \pm 0.14$ & $<0.0001$ \\
Hemoglobin, g/l & $13.8 \pm 0.12$ & $11.4 \pm 0.14$ & $<0.0001$ \\
Smoking, pack-years & $9.3 \pm 2.9$ & $11.1 \pm 1.5$ & $\mathrm{NS}$ \\
Serum calcium, mM & $2.39 \pm 0.01$ & $2.34 \pm 0.01$ & $<0.001$ \\
Serum phosphates, mM & $1.02 \pm 0.02$ & $1.88 \pm 0.03$ & $<0.0001$ \\
\hline
\end{tabular}

Values are means \pm SEM. NS = Nonsignificant.

reflected pressure wave amplitudes. Maximal flow velocity was higher in ESRD patients, whose ascending aortic diameter and aortic peak flow were similar to control values. $\mathrm{Zc}$ and aortic $\mathrm{PWV}$ were higher in ESRD patients. The two groups had comparable left ventricular ejection time and ascending aortic diameters in absolute values. LV outflow tract surface area was smaller in ESRD patients, whose LV outflow velocity integral was higher, but stroke volumes were comparable. CO was larger in ESRD patients in association with higher heart rate (shorter heart period), while $\mathrm{Zr}$ was lower in patients than controls.

Multiple correlation analyses indicated that, for both groups, Zc was correlated positively with aortic PWV $(\mathrm{p}<0.0001)$, negatively with ascending aortic diameter ( $p<0.05$ for controls, $\mathrm{p}<0.0001$ for ESRD; table 3; fig. 1), and, for ESRD patients, positively with age $(\mathrm{p}<0.001)$. While those analyses showed that $\mathrm{Zc}$ was not correlated with mean BP, aortic PWV was significantly associated with MBP and age for controls and ESRD patients with a more pronounced impact of age and pressure in ESRD patients than controls.

Common carotid artery PP was significantly correlated with Zc (table 4). For controls, carotid PP was significantly associated with aortic PWV (19.5\% of variance), stroke volume (17.6\% of variance) and augmentation in$\operatorname{dex}(9.6 \%$ of variance), but not with aortic diameter. For
Table 2. Hemodynamic parameters

\begin{tabular}{|c|c|c|c|}
\hline Variable & $\begin{array}{l}\text { Controls } \\
(\mathrm{n}=57)\end{array}$ & $\begin{array}{l}\text { ESRD } \\
\text { patients } \\
(\mathrm{n}=140)\end{array}$ & $\begin{array}{l}\mathrm{p} \\
\text { value }\end{array}$ \\
\hline Brachial SBP, mm Hg & $143 \pm 2.8$ & $151 \pm 2.6$ & $<0.017$ \\
\hline Brachial DBP, mm Hg & $87 \pm 1.8$ & $82 \pm 1.2$ & 0.015 \\
\hline Brachial mean BP, mm Hg & $106 \pm 2.0$ & $105 \pm 1.5$ & NS \\
\hline Brachial pulse pressure, $\mathrm{mm} \mathrm{Hg}$ & $56 \pm 2.1$ & $69 \pm 2.1$ & $<0.0001$ \\
\hline CCA SBP, mm Hg & $135 \pm 3.0$ & $143 \pm 2.4$ & 0.019 \\
\hline CCA pulse pressure, $\mathrm{mm} \mathrm{Hg}$ & $49 \pm 2.2$ & $61 \pm 1.9$ & $<0.0001$ \\
\hline CCA augmentation index, $\%$ & $15.6 \pm 2.0$ & $25.1 \pm 1.2$ & $<0.0001$ \\
\hline CCA-Pf, mm Hg & $37 \pm 1.5$ & $45 \pm 1.4$ & $<0.0001$ \\
\hline CCA-Pr, mm Hg & $11.5 \pm 0.8$ & $15.4 \pm 0.7$ & $<0.001$ \\
\hline $\mathrm{Zc}$, dyne $\cdot \mathrm{s} \cdot \mathrm{cm}^{-5}$ & $166 \pm 8$ & $214 \pm 8.5$ & $<0.0001$ \\
\hline $\mathrm{Zr}$, dyne $\cdot \mathrm{s} \cdot \mathrm{cm}^{-5}$ & $2,293 \pm 67$ & $2,126 \pm 68$ & 0.015 \\
\hline Heart period, ms & $962 \pm 19$ & $882 \pm 12$ & $<0.001$ \\
\hline $\begin{array}{l}\text { LV outflow tract surface area } \\
\mathrm{cm}^{2}\end{array}$ & $1.90 \pm 0.03$ & $1.75 \pm 0.03$ & $<0.001$ \\
\hline $\begin{array}{l}\text { LV outflow velocity integral } \\
\mathrm{cm} / \text { beat }\end{array}$ & $21.5 \pm 0.6$ & $26.8 \pm 0.6$ & $<0.0001$ \\
\hline Stroke volume, ml & $84 \pm 2.0$ & $84 \pm 1.70$ & NS \\
\hline Cardiac output, $1 / \mathrm{min}$ & $5.32 \pm 0.15$ & $5.78 \pm 0.12$ & $<0.01$ \\
\hline Peak flow velocity, $\mathrm{cm} / \mathrm{s}$ & $107 \pm 2.5$ & $129 \pm 2.5$ & $<0.0001$ \\
\hline Peak flow $\left(\mathrm{Q}_{\max }\right), \mathrm{ml} / \mathrm{s}$ & $309 \pm 10$ & $311 \pm 9$ & NS \\
\hline LVET, ms & $306 \pm 5$ & $306 \pm 4$ & NS \\
\hline Aortic PWV, m/s & $9.61 \pm 0.24$ & $10.78 \pm 0.22$ & $<0.001$ \\
\hline Ascending aortic diameter, $\mathrm{mm}$ & $28 \pm 0.04$ & $28 \pm 0.03$ & NS \\
\hline
\end{tabular}

Values are means \pm SEM. NS = Nonsignificant; CCA = common carotid artery; LVET = left ventricular ejection time.

controls, those variables accounted for $54.3 \%$ of carotid PP variance. For ESRD patients, carotid PP was associated positively with aortic PWV (16\% of variance), augmentation index (5.5\% of variance), age (7.2\% of variance), MBP (14.4\% of variance) and, more weakly with stroke volume. For ESRD patients, negative association was observed between carotid PP and aortic diameter ( $4.7 \%$ of variance). For ESRD patients, those variables accounted for $61.2 \%$ of carotid PP variance (fig. 2).

\section{Discussion}

Elevated PP is a strong independent CV risk in hypertensive individuals and ESRD patients [1,2]. Isolated systolic hypertension and high $\mathrm{PP}$ are characteristic of ESRD patients, and central artery PP (common carorid artery) has been shown to be a strong predictor of all-cause and CV mortality in ESRD [2]. It is generally accepted that 
Fig. 1. Correlations between characteristic impedance and age, MBP, aortic PWV, and ascending aortic diameter. Dashed lines and gray squares are ESRD patients, black circles and solid lines are controls. For statistical significance, see table 3 .

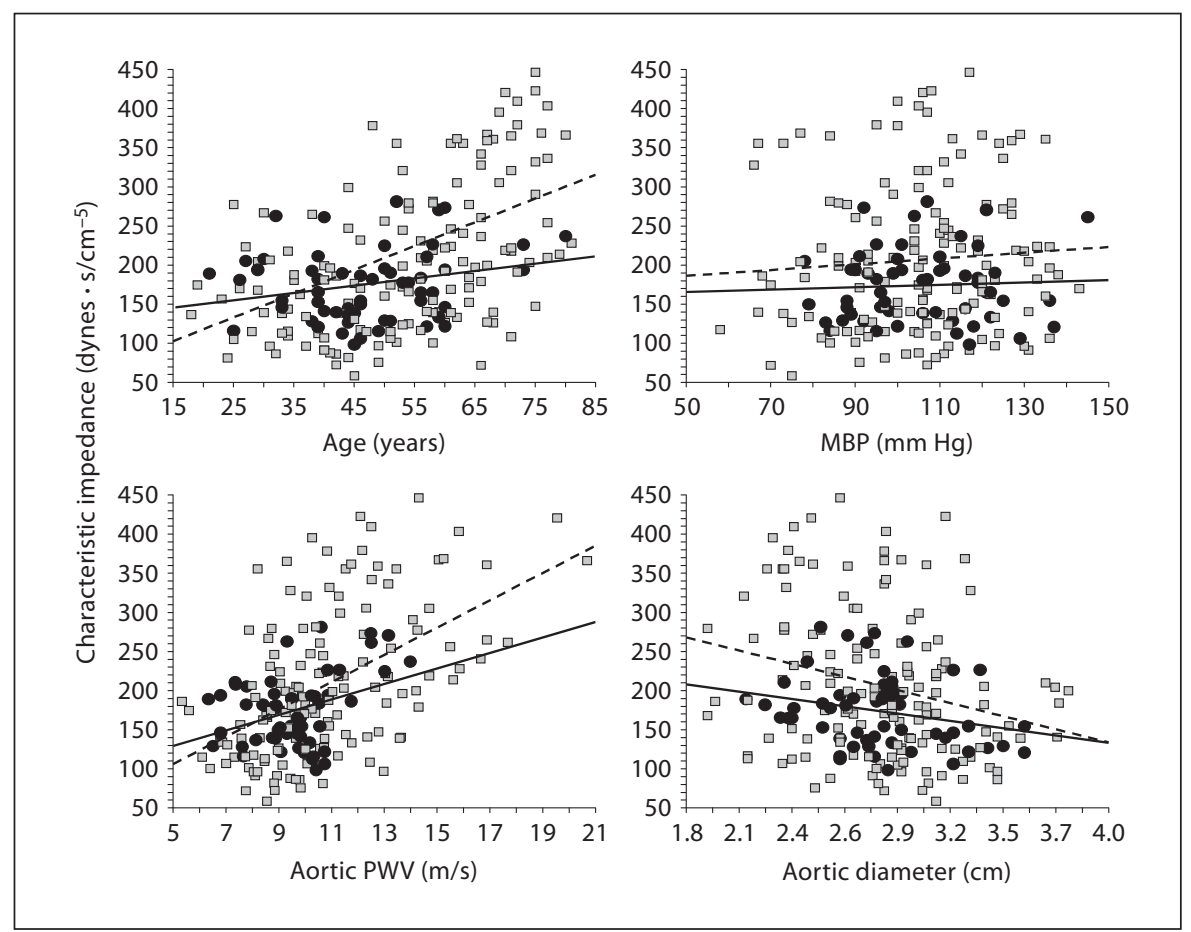

Table 3. Multiple stepwise regression analysis for variables associated with characteristic impedance in controls and ESRD patients

\begin{tabular}{llllll}
\hline Variable & \multicolumn{2}{l}{ Controls } & & \multicolumn{2}{l}{ ESRD patients } \\
\cline { 2 - 3 } \cline { 6 - 7 } & $\mathrm{R}^{2}$ value & $\mathrm{p}$ value & & $\mathrm{R}^{2}$ value & $\mathrm{p}$ value \\
\hline Aortic PWV $(\mathrm{m} / \mathrm{s})$ & 0.226 & $<0.001$ & & 0.136 & $<0.0001$ \\
Aortic diameter $(\mathrm{cm})$ & 0.062 & $<0.05$ & & 0.154 & $<0.0001$ \\
Age (years) & 0.01 & $\mathrm{NS}$ & & 0.120 & $<0.0001$ \\
MBP (mm Hg) & 0.01 & $\mathrm{NS}$ & & 0.01 & $\mathrm{NS}$ \\
Sex $(0$-male; 1-female) & 0.02 & $\mathrm{NS}$ & & 0.02 & $\mathrm{NS}$ \\
Body surface area $\left(\mathrm{m}^{2}\right)$ & 0.02 & $\mathrm{NS}$ & 0.02 & $\mathrm{NS}$ \\
\hline
\end{tabular}

$\mathrm{R}^{2}$ for controls, 0.280; $\mathrm{R}^{2}$ for ESRD patients, 0.496.

high SBP and PP are consequences of aortic stiffening attributed to elastic fiber breakdown with age, leading to rigidity of the vessel wall in parallel with artery diameter increase. However, the pathogenesis of increased SBP and central PP in hypertension remains a matter of debate on the roles of aortic stiffness, aortic diameter, and wave reflections [9].

In controls, only 3 factors affected carotid PP: stroke volume, augmentation index and aortic PWV, which accounted for $54.3 \%$ of PP variability. Aortic diameter played no significant role. For ESRD subjects, the role of stroke volume and aortic diameter were significant but weak, while wave reflections and aortic stiffness, together with age and MBP were strong determinants of higher $\mathrm{PP}$, accounting for $61.2 \%$ of PP variability.

Clinical estimation of aortic stiffness usually involves measurements of PWV, which determines the speed of wave propagation in an artery, or $\mathrm{Zc}$, which determines the early SBP rise associated with a given pulsatile flow prior to the return of any reflected waves [8]. These interrelated measurements of arterial function differ considerably in their relationships to arterial lumen radius:

$$
\mathrm{PWV}=\mathrm{k}(\mathrm{Eh} / \mathrm{R})^{1 / 2} \quad \mathrm{Zc}=\mathrm{k}\left(\mathrm{Eh} / \mathrm{R}^{5}\right)^{1 / 2}
$$

where $\mathrm{E}=$ elastic modulus, $\mathrm{h}=$ arterial wall thickness, and $\mathrm{R}=$ arterial radius.

An increase in vascular smooth muscle (VSM) tone generally has little effect on PWV because the lower R (which reduces wall tension) is countered by increases in medial thickness (h) and the intrinsic alteration of $\mathrm{E}$ caused by VSM contraction. In contrast, Zc invariably rises substantially with local VSM activation because of the amplified (5-fold greater) dependency of Zc on R [4, 8]. Any process that primarily enhances effective arterial wall stiffness (E) will limit the $\mathrm{R}$ increase at a given distending pressure, and will therefore have a greater impact 
Fig. 2. Correlations between common carotid artery $\mathrm{PP}$ and MBP, aortic PWV, aortic ascending diameter, and common carotid artery augmentation index. Dashed lines and gray squares are ESRD patients, black circles and solid lines are controls. For statistical significance, see tables 3 and 4 .

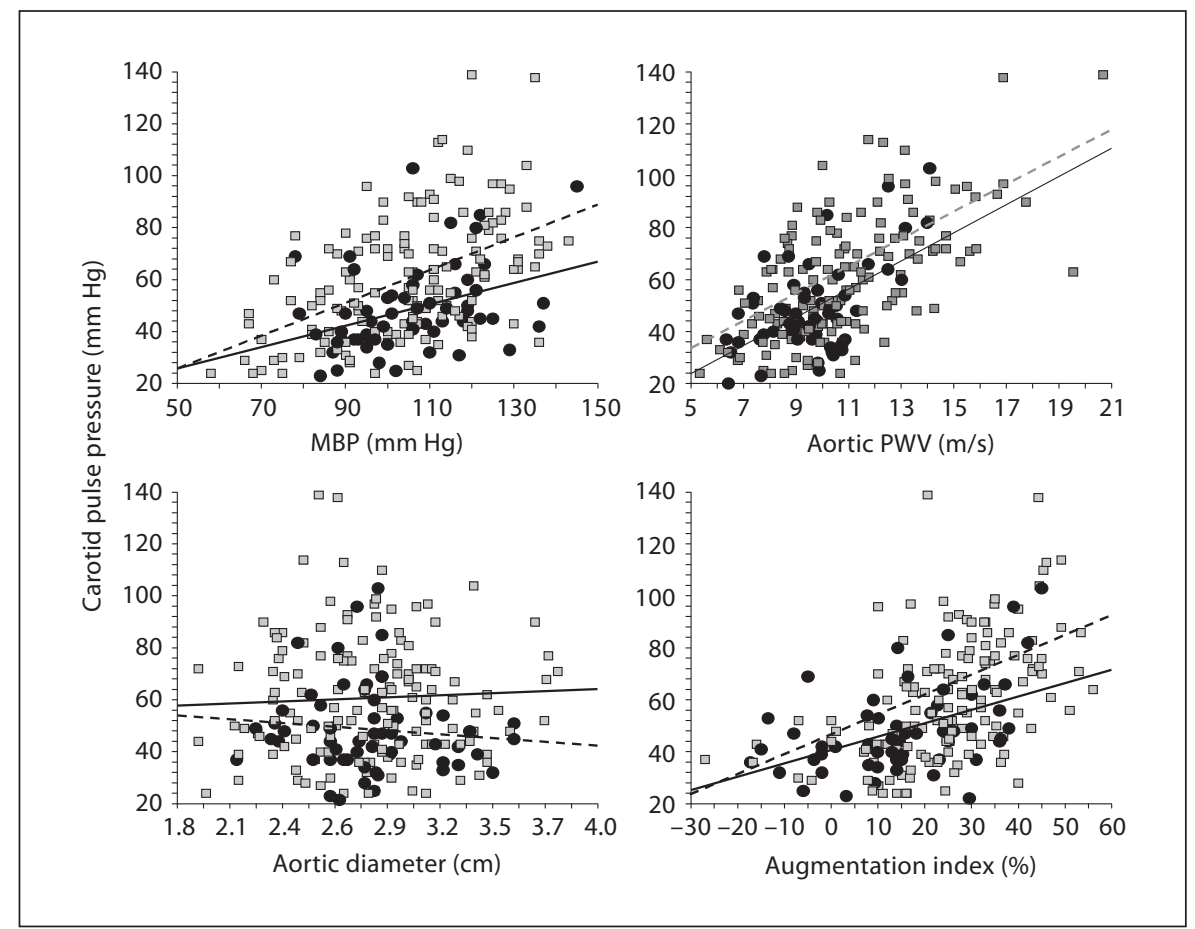

Table 4. Multiple stepwise regression for variables associated with common carotid artery PP in controls and ESRD patients

\begin{tabular}{|c|c|c|c|c|c|c|}
\hline \multirow[t]{2}{*}{ Variable } & \multicolumn{3}{|l|}{ Controls } & \multicolumn{3}{|l|}{ ESRD patients } \\
\hline & $\beta$-coefficient & $\mathrm{R}^{2}$ value & $\mathrm{p}$ value & $\beta$-coefficient & $\mathrm{R}^{2}$ value & $\mathrm{p}$ value \\
\hline Age (years) & $-0.07 \pm 0.16$ & 0.01 & NS & $0.38 \pm 0.12$ & 0.072 & $<0.01$ \\
\hline MBP (mm Hg) & $-0.03 \pm 0.16$ & 0.01 & NS & $0.45 \pm 0.09$ & 0.144 & $<0.0001$ \\
\hline Aortic diameter $(\mathrm{cm})$ & $-7.8 \pm 5.8$ & 0.034 & NS & $-9.85 \pm 3.8$ & 0.047 & 0.015 \\
\hline Stroke volume $(\mathrm{ml})$ & $0.40 \pm 0.12$ & 0.176 & $<0.001$ & $0.14 \pm 0.07$ & 0.03 & $<0.05$ \\
\hline Augmentation index (\%) & $0.35 \pm 0.15$ & 0.096 & 0.014 & $0.30 \pm 0.10$ & 0.055 & $<0.01$ \\
\hline Aortic PWV $(\mathrm{m} / \mathrm{s})$ & $4.85 \pm 1.40$ & 0.195 & $<0.001$ & $3.40 \pm 0.64$ & 0.167 & $<0.0001$ \\
\hline
\end{tabular}

Whole model $\mathrm{R}^{2}$ values: for controls, 0.543 ; for ESRD patients, 0.612. NS = Nonsignificant.

on $\mathrm{Zc}$ than PWV. Furthermore, the in vivo regional response to increased VSM tone is complicated by the associated MBP changes [4, 8]. A localized increase in VSM tone would tend to increase $\mathrm{Zc}$, noted above. However, when $\mathrm{MBP}$ rises because of associated resistance changes in vessel tone, large artery diameter and $\mathrm{Zc}$ may remain unchanged (or increase), while PWV is likely to rise because of the attenuated dependency of PWV on R. Thus, $\mathrm{PWV}$ is also more dependent on $\mathrm{BP}$ than $\mathrm{Zc}$ is.

Carotid PP was considered the summation of an incident and a reflected wave interacting with the heart. It was shown that (a) the stroke volume, which is located on the incident wave, had mild effect on PP in ESRD patients, unlike normal subjects; (b) aortic diameter did not interfere with PP variability in controls, but played a significant but weak role in ESRD patients, in whom it was positively associated with aortic stiffness; (c) although aortic diameter was not influenced by age and MBP, those two factors influenced markedly PWV; (d) finally, wave reflections represented a significant determinant of carotid PP in both groups. Taken together, these results suggest that aortic stiffness and wave reflections strongly in-

Blood Purif 2011:31:107-112 
fluenced carotid PP in both groups, and that, only in ESRD patients, did the aortic diameter increase to 'compensate' for aortic stiffening.

These observations differ from those made on elderly subjects in general populations $[9,10]$. In those subjects, aortic diameter was inversely associated with PP, indicating that a small aortic diameter might contribute to the pathophysiology of elevated PP and systolic hypertension. Nevertheless, in a recent large community-based sample of nonhypertensive individuals, aortic root diameter was not prospectively associated with hypertension onset or BP progression after adjustment for potential confounders [11].

While stroke volume is an important variable associated with PP in control subjects, its role was weak in ESRD patients, suggesting that intrinsic infraclinical LV dysfunction is already present in asymptomatic ESRD patients [5].

Increased carotid $\mathrm{PP}$ is an independent predictor of $\mathrm{CV}$ risk both in ESRD patients and in the elderly. However, whereas in ESRD patients carotid stiffness was also an independent predictive CV factor [3], it was not the case in the elderly controls [12-14]. In these patients, only carotid diameter, and not stiffness, was a predictor of risk in association with increased carotid PP, with the exception of the short study by Stork et al. [15]. In our study, central PP was significantly associated with arterial stiffening, wave reflections and LV ejection volume in ESRD and controls. The role of aortic diameter was apparent only in ESRD patients, and seems to be a compensation for increased stiffness, as suggested by the positive relationship between aortic PWV and diameter in these patients. These results seem to contradict those observed in elderly general populations, in which aortic dimensions as a determinant of central PP seemed to have a greater part to play $[9,10]$. A possible explanation lies in the phenomenon of accelerated arterial aging in ESRD [16]. Indeed the present populations are middle aged, and the role of aortic dimensions in PP observed in general populations concerned elderly patients. Those examples indicate that artery structure and function differ markedly in the general population and ESRD patients, with premature ageing in the latter. In ESRD patients, the extent of vascular calcifications may contribute to this difference [17].

\section{References}

1 Franklin SS, Wilkinson JB, Cockroft JR: Brachial and central pulse pressure, and cardiovascular risk; in Safar ME, O'Rourke MF (eds): Arterial Stiffness in Hypertension. Edinburgh, Elsevier, 2006, pp 225-224.

-2 Safar ME, Blacher J, Pannier B, Guérin AP, Marchais SJ, Guyonvarc'h PM, London GM: Central pulse pressure and mortality in endstage renal disease. Hypertension 2002;39: 735-738.

-3 Blacher J, Pannier B, Guerin AP, Marchais SJ, Safar ME, London GM: Carotid arterial stiffness as a predictor of cardiovascular and all-cause mortality in end-stage renal disease. Hypertension 1998;32:570-574.

4 Izzo JL, Mitchell GF: Aging and arterial structure-function relations; in Safar ME, Frohlich ED (eds): Atherosclerosis, Large Arteries and Cardiovascular Risk. Adv Cardiol. Basel, Karger, 2007, vol 44, pp 19-34.

5 London GM, Guerin AP, Marchais SJ, Pannier B, Safar ME, Day M, Metivier F: Cardiac and arterial interactions in end-stage renal disease. Kidney Int 1996;50:600-608.

6 London GM, Cohn JN: Prognostic application of arterial stiffness: task forces. Am J Hypertens 2002;15:754-758.

7 Smulyan H, Siddiqui DS, Carlson RJ, London GM, Safar ME: Clinical utility of aortic pulses and pressures calculated from applanated radial-artery pulses. Hypertension 2003;42:150-155
8 Nichols WW, O'Rourke MF: Wave reflection; in Nichols WW, O'Rourke MF: McDonald's Blood Flow in the Arteries, ed 5. London, Hodder Arnold Publishers, 2005, pp 195-211.

-9 Mitchell GF, Lacourciere Y, Ouellet JP, Izzo JL Jr, Neutel J, Kerwin LJ, Block AJ, Pfeffer MA: Determinants of elevated pulse pressure in middle-aged and older subjects with uncomplicated systolic hypertension: the role of proximal aortic diameter and the aortic pressure-flow relationship. Circulation 2003;108:1592-1598.

10 Farasat SM, Morrell CH, Scuteri A, Ting CT, Yin FC, Spurgeon HA, Chen CH, Lakatta EG, Najjar SS: Pulse pressure is inversely related to aortic root diameter implications for the pathogenesis of systolic hypertension. Hypertension 2008;51:196-202.

-11 Ingelsson E, Pencina MJ, Levy D, Aragam J, Mitchell GF, Benjamin EJ, Varsan RS: Aortic root diameter and longitudinal blood pressure tracking. Hypertension 2008;52:473477.

12 Dijk JM, Algra A, van der Graaf Y, Grobbee DE, Bots ML: Carotid stiffness and the risk of new vascular events in patients with manifest cardiovascular disease. The SMART study. Eur Heart J 2005;26:1213-1220.
$>13$ Leone N, Ducimetiere P, Gariepy J, Courbon D, Tzourio C, Dartigues JF, Ritchie K, Alperovitch A, Amouyel P, Safar ME, Zureik $\mathrm{M}$ : Distension of the carotid artery and risk of coronary events: the three-city study. Arterioscler Thromb Vasc Biol 2008;28:13921397.

14 Mattace-Raso FU, van der Cammen TJ, Hofman A, van Popele NM, Bos ML, Schalekamp MA, Asmar R, Reneman RS, Hoeks AP, Breteler MM, Witteman JC: Arterial stiffness and risk of coronary heart disease and stroke: the Rotterdam Study. Circulation 2006;113: 657-663.

15 Stork S, van den Beld AW, von Schacky C, Angermann CE, Lamberts SW, Grobbee DE, Bots ML: Carotid artery plaque burden, stiffness, and mortality risk in elderly men: a prospective, population-based cohort study. Circulation 2004;110:344-348.

16 Pannier B, Guérin AP, Marchais SJ, Métivier F, London GM: Arterial stricture and function in end-stage renal disease. Artery Res 2007;1:79-88.

17 London GM, Marchais SJ, Guerin AP, Boutouyrie P, Metivier F, de Vernejoul MC: Association of bone activity, calcium load, aortic stiffness, and calcifications in ESRD. J Am Soc Nephrol 2008;19:1827-1835. 